\title{
Antioxidants extraction from Pinhão (Araucaria angustifolia (Bertol.) Kuntze) coats and application to zein films
}

\author{
Tânia Barbedo De Freitas ${ }^{\mathrm{a}}$, Carlos Henrique Koslinski Santos ${ }^{\mathrm{b}}$, Marcos Vieira da Silva ${ }^{\mathrm{a}}$, \\ Marianne Ayumi Shirai ${ }^{\mathrm{b}}$, Maria Inês Dias ${ }^{\mathrm{c}}$, Lillian Barros ${ }^{\mathrm{c}}$, Maria Filomena Barreiro ${ }^{\mathrm{d}}$, \\ Isabel C.F.R. Ferreira ${ }^{c}$, Odinei Hess Gonçalves ${ }^{\mathrm{b}, \mathrm{d}}$, Fernanda Vitória Leimann ${ }^{\mathrm{b}, \mathrm{d}, *}$

\begin{abstract}
a Departamento Acadêmico de Alimentos (DALIM), Universidade Tecnológica Federal do Paraná, Campus Campo Mourão (UTFPR-CM), via Rosalina Maria Dos Santos, 1233, CEP 87301-899, Caixa Postal: 271, Campo Mourão, Paraná, Brazil

b Programa de Pós-Graduação em Tecnologia de Alimentos (PPGTA), Universidade Tecnológica Federal do Paraná, Campus Campo Mourão (UTFPR-CM), via Rosalina Maria Dos Santos, 1233, CEP 87301-899, Caixa Postal: 271, Campo Mourão, Paraná, Brazil

c Centro de Investigação de Montanha (CIMO), Instituto Politécnico de Bragança, Campus de Santa Apolónia, 5300-253, Bragança, Portugal

d Laboratory of Separation and Reaction Engineering - Laboratory of Catalysis and Materials (LSRE-LCM), Instituto Politécnico de Bragança, Campus de Santa Apolónia,
\end{abstract} \\ 5301-857, Bragança, Portugal
}

\section{A R T I C L E I N F O}

\section{Keywords:}

Phenolic compounds

Active packaging

Microstructure

Plasticizing effect

\begin{abstract}
A B S T R A C T
Seeds from Araucaria angustifolia (Bertol.) Kuntze are consumed after cooking and their coats discarded. Both coats and the cooking water present phenolic compounds, which may be used to improve mechanical properties and provide antioxidant characteristics to films. The objective of this work was to obtain and pinhão coat extracts and to apply these polyphenolic-rich extracts in zein films. Phenolic compounds composition, extraction yield and antioxidant activity (DPPH, ABTS and FRAP) of the extracts were determined. The most abundant molecules present in the hydroethanolic extract were $(+)$-catechin and an (epi)catechin dimer, whereas protocatechuic acid were predominant in the both cooking water and ethanolic extracts. Glass transition temperature of zein was not found in the extract-loaded films. Morphological changes were also caused by the presence of the extracts yielding smoother surfaces. The extracts added to zein films led to a three-fold increase in tensile strength (from 5.80 MPa to $17.65 \mathrm{MPa}$ ) and two-fold increase in the elongation at break (from $1.60 \%$ to $3.18 \%)$.
\end{abstract}

\section{Introduction}

Seeds produced by Araucaria angustifolia (Bert.) O. Kuntze (Paraná tree), referred to as "pinhão", are formed by a resistant external tegument (shell or coat) composed of lignocellulosic material rich in tannins and an internal edible pulp (Bello-Pérez et al., 2006; Conforti \& Lupano, 2008; Lima et al., 2007; Santos et al., 2013). Seeds are produced seasonally and typically consumed after boiled in water. Although pinhão production is not an organized culture (Conab, 2014), there is an increasing interest in the industrial development of pinhão based products, such as pickled pinhão (Riele Conservas, 2016; WWC, 2016) and beverages such as beer (Cervejaria Campos do Jordão, 2016). In 2007, Brazil generated about 10 ton of pinhão wastes (Lima et al., 2007).

Residual pinhão coats, which represent about $20 \%$ of the weight (Conforti \& Lupano, 2008; Cordenunsi et al., 2004), has also been attracting interest due to its antioxidant properties and potential biological activity. da Mota et al. (2014) obtained methanolic extracts from the shell and pulp of A. angustifolia seeds and identified in both extracts the presence of molecules with free radicals-trapping ability (e.g. polyphenolic compounds, flavonoids and proanthocyanins). The biological activity of pinhão extracts was reported by da Silva et al. (2014) who investigated the efficacy of a pinhão coat extract (70\% ethanol in water) to decrease the postprandial glycemic levels in rats after starch administration. Authors claimed that the extract may be potentially used to suppress postprandial hyperglycemia in diabetic patients due to its inhibitory properties. In the study developed by Oliveira et al. (2015), a pinhão coat extract proved to be an effective inhibitor of pancreatic lipase and to effectively decrease plasma triglyceride levels in mice after a load of olive oil. Also, Branco et al. (2015) demonstrated that an aqueous extract of $A$. angustifolia bracts presented selective cytotoxicity and pro-apoptotic activity in laryngeal carcinoma HEp-2 cells.

The application of phenolic compounds in film formulations to obtain antioxidant properties, or active packaging materials, has been widely studied. For instance, studies have been published on gelatin-

\footnotetext{
* Corresponding author.

E-mail address: fernandaleimann@utfpr.edu.br (F.V. Leimann).
} 
based films added with curcuma ethanol extract (Bitencourt, FávaroTrindade, Sobral, \& Carvalho, 2014), low density polyethylene incorporated with rosemary extract and natural extracts obtained from a brewery residual waste (Barbosa-Pereira, Aurrekoetxea, Angulo, Paseiro-Losada, \& Cruz, 2014), starch-based films with propolis extract (De Araújo et al., 2015), and zein and chitosan matrices supplemented with phenolic compounds (ferulic and gallic acids, respectively) (Cheng, Wang, \& Weng, 2015).

Zein films may serve as carriers for antioxidant compound in food packaging applications (Arcan \& Yemenicioğlu, 2011; Forato, Britto, Scramin, Colnago, \& Assis, 2013; Park et al., 2012). In zein films, for instance, the addition of gallic acid, $p$-hydroxy benzoic acid, ferulic acid, flavone, (+)-catechin, and quercetin (Arcan and Yemenicioğlu, 2011), butylated hydroxyanisole and butylated hydroxytoluene (Kleen, Pauda, \& Engeseth, 2002), green tea extract (Lee, Lee, \& Song, 2004), gallic acid (Neo et al., 2013), and ferulic acid and gallic acid (Cheng et al., 2015) have been reported. However, to the best of our knowledge polyphenolic compounds from pinhão extracts have not yet been applied in films formulation as a carrier of antioxidant substances. In such case, the actual impact of the extracts on the films properties must also be determined. Also, applications involving zein films are worth investigating since zein is an important co-product of maize starch production, as well as a by-product of the bioethanol industry.

In this context, the current work aimed to obtain and to characterize pinhão coat extracts as well as to apply these extracts as a source of natural polyphenolic compounds in zein films. Extracts were obtained from the cooking water extract and also by subsequent ethanolic and hydroethanolic extraction of the residual pinhão coats.

\section{Materials and methods}

\subsection{Materials}

Pinhão seeds were acquired from the local market in Brazil in June 2015. Zein, Folin-Ciocalteu reagent, gallic acid, 2,2-diphenyl-1-picrylhydrazyl (DPPH), ferric reducing/antioxidant power (FRAP) reagent [0.3 M acetate buffer, pH 3.6 and $10 \mathrm{mM}$ 2,4,6-tris(2-pyridyl)-striazine (TPTZ)], Trolox (6-hydroxy-2,5,7,8-tetramethychroman-2-carboxylic acid), ABTS (2,2'-azinobis [3-ethylbenzothiazoline-6-sulfonic acid] diammonium salt) and potassium persulfate (dipotassium peroxydisulfate) were purchased from Sigma-Aldrich. Glycerol, calcium carbonate and ethanol (Vetec) were analytical grade. Acetonitrile (99.9\%, Fisher Scientific, HPLC grade) was used in the chromatographic analyses. Formic acid was purchased from Panreac Química SLU. (Barcelona, Spain). Phenolic standards were from Extrasynthèse (Genay, France). Water was treated in a Milli-Q water purification system (TGI Pure Water Systems, USA).

\subsection{Pinhão preparation and antioxidant extraction}

Pinhão seeds $(526 \mathrm{~g})$ were cooked in water $(1 \mathrm{~L})$ for $2 \mathrm{~h}$, using a pressure cooker. Seeds were recovered using a sieve and the extract (cooking water, $\mathrm{CW}$ ) was frozen $\left(-18^{\circ} \mathrm{C}\right)$.

The cooked pinhão seeds were opened and their coats dried in a forced air convection oven (Cienlab, Brazil) at $40{ }^{\circ} \mathrm{C}$ for $24 \mathrm{~h}$. Thereafter, they were crushed in a domestic blender and classified using a vibrating set of sieves $(200 /+400$ mesh Tyler). The resultant material was stored in the freezer $\left(-18{ }^{\circ} \mathrm{C}\right)$ until extraction.

The antioxidant ethanolic (EtOH) and hydroethanolic extracts (HA) were prepared using pure ethanol and an $80 \%(\mathrm{v} / \mathrm{v})$ hydroethanolic mixture, respectively. First, sieved pinhão coats $(5 \mathrm{~g})$ and solvent $(120 \mathrm{~g})$ were stirred using a magnetic stirrer for $5 \mathrm{~h}$. Extraction yield $(\%, \mathrm{w} / \mathrm{w})$ was determined gravimetrically. All extraction procedures were carried out in triplicate.

\subsection{Antioxidant activities}

The antioxidant activity of the extracts was assessed by the ABTS and DPPH radical scavenging assays. The ABTS assay was based on the method of Arnao, Cano, and Acosta (2001), as adapted by Thaipong, Boonprakob, Crosby, Cisneros-Zevallos, and Hawkins Byrne (2006). First, a stock solution was prepared from equal volumes of aqueous solutions of $7.4 \mathrm{mM}$ ABTS and $2.6 \mathrm{mM}$ sodium persulfate. The stock solution was kept in the dark for $12 \mathrm{~h}$ to allow the formation of the ABTS radical $\left(\mathrm{ABTS}^{+}\right.$), then diluted with methanol until an absorbance of $1.100 \pm 0.010$ units at $734 \mathrm{~nm}$ was reached (Ocean Optics, Red Tide USB650 Fiber Optic Spectrometer, USA) to form the working solution. In test tubes, $2.85 \mathrm{~mL}$ of the working solution was added to $150 \mu \mathrm{L}$ of the extract (or $150 \mu \mathrm{L}$ ethanol as the control). After homogenization, the solutions were stored in the dark for $2 \mathrm{~h}$ and the absorbance at $734 \mathrm{~nm}$ was determined. All samples were analyzed in triplicate. Results were calculated using a previously obtained Trolox calibration curve $\left(50-500 \mu \mathrm{M}, \mathrm{y}=1.0595 \mathrm{x}-0.0017 ; \mathrm{R}^{2}=0.9991\right)$ and expressed as $\mu \mathrm{mol}$ of Trolox equivalent (TE) per $100 \mathrm{~g}$ of pinhão coat $\left(\mu \mathrm{mol}_{\mathrm{TE}} .100 \mathrm{~g}_{\text {pinhão coat }}{ }^{-1}\right)$.

For the DPPH assay, the procedure described by Mensor et al. (2001) was used, with some modifications. In a test tube, $2.5 \mathrm{~mL}$ of the extract was mixed with $1 \mathrm{~mL}$ of $0.3 \mathrm{mM}$ DPPH methanol solution (or pure methanol as the control). After $30 \mathrm{~min}$ in the dark, the absorbance was determined at $518 \mathrm{~nm}$. All samples were analyzed in triplicate. The antioxidant capacity was calculated using a Trolox standard curve $\left(15-75 \mu \mathrm{M}, \mathrm{y}=1.0728 \mathrm{x}-0.0168 ; \mathrm{R}^{2}=0.9977\right)$ and the results expressed as $\mu \mathrm{mol}_{\mathrm{TE}} 100 \mathrm{~g}_{\text {pinhão coat }}{ }^{-1}$.

The FRAP assay was performed according to Benzie and Strain (1996), with minor modifications. First, $100 \mu \mathrm{L}$ of the extract solution (or $100 \mu \mathrm{L}$ of distilled water, for the blank sample) and $300 \mu \mathrm{L}$ distilled water were added to a test tube. Then, $3.0 \mathrm{~mL}$ of FRAP reagent $(10 \mathrm{mM}$ TPTZ in $40 \mathrm{mM} \mathrm{HCl}$, plus $20 \mathrm{mM}$ ferric chloride and $300 \mathrm{mM}$ acetate buffer, $\mathrm{pH} 3.6,1: 1: 10 \mathrm{v} / \mathrm{v} / \mathrm{v}$ ) were added and the solution homogenized and warmed at $37{ }^{\circ} \mathrm{C}$ for $30 \mathrm{~min}$ in a water bath. Finally, the absorbance of the colored product (ferrous tripyridyltriazine complex) was determined at $593 \mathrm{~nm}$. A Trolox standard curve $(50-1000 \mu \mathrm{M}$, $\left.y=0.0013 x+0.0111 ; R^{2}=0.9991\right)$ was prepared and the results

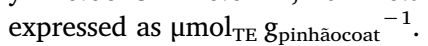

\subsection{Phenolic compound analyses}

The lyophilized extracts were re-dissolved in a 80:20 methanol:water ( $\mathrm{v} / \mathrm{v}$ mixture and the phenolic profile was determined by highperformance liquid chromatography-diode array detection-electrospray ionization multi-stage mass spectrometry (HPLC-DAD-ESI)/MSn (Dionex Ultimate 3000 UPLC, Thermo Scientific, San Jose, CA, USA) as previously described by Bessada, Barreira, Barros, Ferreira, \& Oliveira (2016). Double online detection was carried by DAD using 280 and $370 \mathrm{~nm}$ as the preferred wavelengths and a mass spectrometer connected to the HPLC system via the DAD cell outlet. The MS detection was performed in negative ion mode, using an LTQ XL linear ion trap mass spectrometer (Thermo Finnigan, San Jose, CA, USA) equipped with an ESI source. Positive identification of the phenolic compounds was performed using standard compounds, when available, by comparing their retention times, UV-vis and mass spectra. Also, tentative identification was made based on data reported in the literature. For quantitative analysis, a calibration curve, obtained for each available phenolic standard, was constructed based on the UV signal. For the phenolic compounds identified in the absence of an available commercial standard, quantification was performed based on the calibration curve of the most similar available standard. Results were expressed as $\mathrm{mg} \mathrm{g}_{\text {extract }}{ }^{-1}$. 
Table 1

Zein film formulations: FC- zein control film; FCW-zein film with pinhão cooking water; FEtOH- zein film with pinhão ethanol extract; FHA- zein film with pinhão hydroethanolic extract.

\begin{tabular}{lllll}
\hline Formulation & FC & FCW & FEtOH & FHA \\
\hline Zein $(\mathrm{g})$ & 19.2 & 19.2 & 19.2 & 19.2 \\
Glycerol (g) & 3.8 & 3.8 & 3.8 & 3.8 \\
Water (g) & 20 & - & 20 & - \\
Ethanol (g) & 80 & 80 & - & - \\
Pinhão cooking water (CW) (g) & - & 20 & - & - \\
Pinhão coat ethanol extract (EtOH) (g) & - & - & 80 & - \\
Pinhão coat hydro-alcoholic extract (HA) (g) & - & - & - & 100 \\
\hline
\end{tabular}

\subsection{Zein film preparation}

Zein films were prepared by film casting according to Phiriyawirut and Maniaw (2012), with some modifications. Table 1 presents the used formulations. For the control formulation (FC), zein (19.2 g) was solubilized in a $80 \% \mathrm{v} / \mathrm{v}$ ethanol in water solution $(100 \mathrm{~g})$ by homogenization (Ultra-Turrax T25, IKA, USA) at $3000 \mathrm{rpm}$ during $5 \mathrm{~min}$. Next, glycerol ( $3.8 \mathrm{~g}$ ) was added and the final solution degassed in an ultrasonic bath (Cristófoli, Brazil) for $15 \mathrm{~min}$. The solution was then poured into teflon pans $(32 \times 22 \mathrm{~cm})$ and oven-dried $\left(50{ }^{\circ} \mathrm{C}\right.$ for $\left.24 \mathrm{~h}\right)$. For the films containing CW, EtOH and HA extracts (referred herein as FCW, FEtOH and FHA, respectively) the same procedure was adopted with the ethanol in water solution being replaced by the corresponding extracts according to the formulations presented in Table 1.

\subsection{Antioxidant activity of the films}

The antioxidant activity (DPPH, ABTS and FRAP) of the films were performed as described in Section 2.3, following an extraction procedure according to the method described by De Araújo et al. (2015). Briefly, ethanol $(30 \mathrm{~mL})$ was added to the film sample $(1.5 \mathrm{~g})$ homogenized using an Ultra-Turrax at $16,000 \mathrm{rpm}$ for $5 \mathrm{~min}$ followed by stirring at $6000 \mathrm{rpm}$ for $15 \mathrm{~min}$. The solution was centrifuged (NT825 Nova Técnica, Brazil) at $6000 \mathrm{rpm}$ for $15 \mathrm{~min}$ and the supernatant collected. The extraction was repeated twice, by adding ethanol $(30 \mathrm{~mL})$ to the centrifuged precipitate. The three resulting ethanol fractions were stored at $-20{ }^{\circ} \mathrm{C}$. Antioxidant results were expressed as $\mu \mathrm{mol}_{\mathrm{TE}} \mathrm{g}_{\text {filmsample }}{ }^{-1}$.

\subsection{Mechanical properties of the films}

The tensile strength tests were performed using a TA-XT Express Enhanced texture analyzer (TA-XT Express Enhanced, Texture Analyzer - Stable Micro Systems, UK) based on the American Society for Testing and Material Standards (ASTM, 2002). Ten samples $(50 \times 10 \mathrm{~mm})$ of each formulation were pre-conditioned at $23 \pm 2{ }^{\circ} \mathrm{C}$ and $53 \%$ relative humidity for $48 \mathrm{~h}$. Sheet thickness was determined using a digital micrometer (Starrett, $0.001 \mathrm{~mm}$ resolution). For each sample, ten random points were measured. Tensile strength (MPa), elongation at break (\%), and Young's modulus (MPa) were evaluated.

\subsection{Water solubility of the films}

Water solubility is defined as the dry mass content obtained from film samples that were solubilized by immersion in water at $25{ }^{\circ} \mathrm{C}$ for $24 \mathrm{~h}$. The adopted procedure was the one described by Pizzoli et al. (2016). Film samples $(2 \times 2 \mathrm{~cm})$ were weighed $\left(\mathrm{m}_{\mathrm{i}}\right.$, dry basis) and then immersed in water $\left(200 \mathrm{~mL}, 25 \pm 2{ }^{\circ} \mathrm{C}\right)$ for $24 \mathrm{~h}$. Next, the residual film was removed and dried at $70{ }^{\circ} \mathrm{C}$ in a forced air oven for $24 \mathrm{~h}$. The samples were then weighed $\left(\mathrm{m}_{\mathrm{f}}\right)$ and the water solubility (SOL\%) was calculated using Eq. (1) on a dry basis.

$S O L=\frac{\left(\left(m_{i}-m_{a}\right)-m_{f}\right)}{\left(m_{i}-m_{a}\right)} \cdot 100$

\subsection{Field emission gun-scanning electron microscopy (FEG-SEM)}

The morphology of the zein films was characterized by FEG-SEM (JEOL JSM-6701F, USA) operating at $5 \mathrm{kV}$. Samples were kept in a desiccator with silica for 2 weeks and then covered with a gold layer, prior to analysis.

\section{Results and discussion}

\subsection{Phenolic compounds in pinhão extracts}

The peak characteristics (retention time, $\lambda_{\max }$ in the visible region, mass spectral data) and tentative identification of the phenolic compounds present in the extracts of $A$. angustifolia (Bertol.) Kuntze. are presented in Table 2. A phenolic profile recorded at $280 \mathrm{~nm}$ is exemplified in Fig. 1. The quantification of the phenolic compounds present in the extracts is shown in Table 3. Thirteen phenolic compounds were identified in all samples, comprising ten proanthocyanidins (catechin and epicatechin derivatives), two phenolic acids (protocatechuic and ferulic acid derivatives), a flavonol (quercetin-3-Oglucoside) and a flavanone (eriodictyol-O-hexoside).

Compounds 3, 6, 9 and 13 were positively identified as protocatechuic acid, (+)-catechin, (-)-epicatechin and quercetin-3-Oglucoside, respectively, according to their retention time, mass and UV-vis characteristics, by comparison with commercial standards. Catechin, (-)-epicatechin and quercetin have been previously identified in Paraná pine (da Silva et al., 2014), whereas protocatechuic acid and quercetin have been previously reported in the dead bark of

Table 2

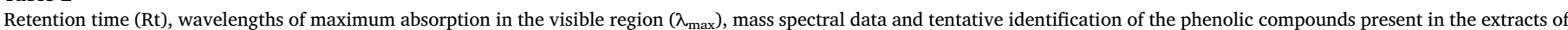
A. angustifolia (Bertol.) Kuntze.

\begin{tabular}{|c|c|c|c|c|c|}
\hline Peak & Rt (min) & $\operatorname{lmax}(\mathrm{nm})$ & {$[\mathrm{M}-\mathrm{H}]^{-}(m / z)$} & $\operatorname{MS} 2(m / z)$ & Tentative identification \\
\hline 1 & 5.01 & 279 & 593 & $575(28), 549(3), 467(36), 441(57), 425(100), 423(31), 407(11), 305(18), 289(8)$ & Prodelphinidin B3 \\
\hline 2 & 5.47 & 280 & 577 & $451(23), 425(100), 407(22), 289(12), 287(10)$ & B-type (epi)catechin dimer \\
\hline 3 & 5.74 & $260 / \operatorname{sh} 292$ & 153 & $109(100)$ & Protocatechuic acid \\
\hline 4 & 6.31 & 280 & 577 & $451(16), 425(100), 407(19), 289(8), 287(7)$ & B-type (epi)catechin dimer \\
\hline 5 & 6.67 & 314 & 355 & 193(100) & Ferulic acid hexoside \\
\hline 6 & 7.21 & 280 & 289 & $245(100), 203(50), 187(10), 161(9), 137(3)$ & $(+)$-Catechin \\
\hline 7 & 7.78 & 280 & 577 & $451(24), 425(100), 407(22), 289(11), 287(10)$ & B-type (epi)catechin dimer \\
\hline 8 & 7.9 & 280 & 577 & $451(18), 425(100), 407(22), 289(9), 287(7)$ & B-type (epi)catechin dimer \\
\hline 9 & 9.89 & 280 & 289 & $245(100), 203(35), 187(6), 161(8), 137(3)$ & (-)-Epicatechin \\
\hline 10 & 11.35 & 279 & 865 & 739(78),713(47),695(100),577(62),575(42),425(12),407(9),289(6),287(11) & B-type (epi)catechin trimer \\
\hline 11 & 12.02 & 281 & 865 & $739(78), 713(56), 695(100), 577(46), 575(82), 425(11), 407(9), 289(6), 287(9)$ & B-type (epi)catechin trimer \\
\hline 12 & 16.49 & $283 / \operatorname{sh} 324$ & 449 & 287(100) & Eriodictyol-O-hexoside \\
\hline 13 & 19.31 & 350 & 463 & $301(100)$ & Quercetin-3-O-glucoside \\
\hline
\end{tabular}




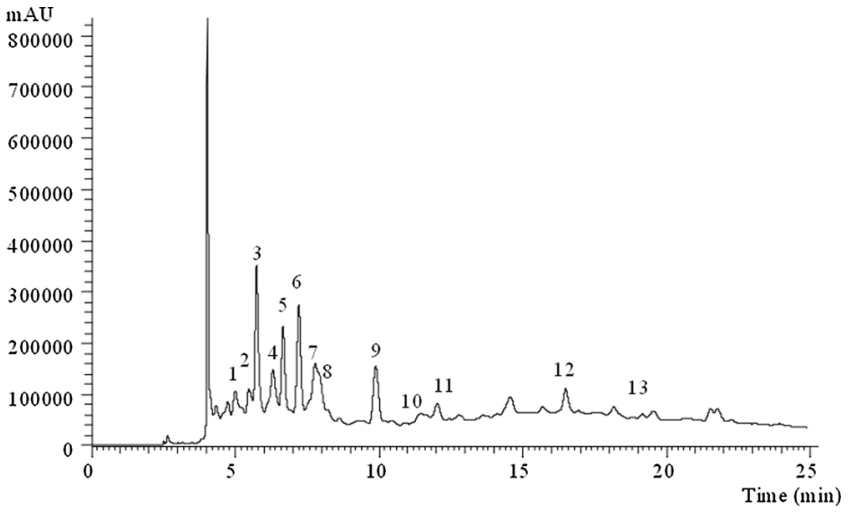

Fig. 1. HPLC phenolic profile of A. angustifolia (Bertol.) Kuntze extract (FHA) obtained at $280 \mathrm{~nm}$.

Table 3

Phenolic compounds quantified (mg/g) in A. angustifolia (Bertol.) Kuntze extracts (mean \pm standard deviation, SD).

\begin{tabular}{|c|c|c|c|}
\hline Compounds & $\mathrm{CW}$ & EtOH & HA \\
\hline Prodelphinidin $\mathrm{B} 3^{1}$ & $1.59 \pm 0.05$ & $0.68 \pm 0.03$ & $2.23 \pm 0.02$ \\
\hline B-type (epi)catechin dimer ${ }^{1}$ & $1.81 \pm 0.02$ & $0.55 \pm 0.04$ & $2.95 \pm 0.10$ \\
\hline Protocatechuic acid ${ }^{2}$ & $4.87 \pm 0.06$ & $2.66 \pm 0.01$ & $2.19 \pm 0.02$ \\
\hline B-type (epi)catechin dimer ${ }^{1}$ & $1.67 \pm 0.06$ & $0.54 \pm 0.03$ & $5.28 \pm 0.07$ \\
\hline Ferulic acid hexoside ${ }^{3}$ & $0.53 \pm 0.02$ & $0.43 \pm 0.01$ & $0.72 \pm 0.03$ \\
\hline$(+)$-Catechin ${ }^{1}$ & $2.06 \pm 0.03$ & $1.20 \pm 0.05$ & $5.84 \pm 0.22$ \\
\hline B-type (epi)catechin dimer ${ }^{1}$ & $1.54 \pm 0.05$ & $4.34 \pm 0.03$ & $2.49 \pm 0.05$ \\
\hline B-type (epi)catechin dimer ${ }^{1}$ & $2.19 \pm 0.06$ & nd & $3.35 \pm 0.03$ \\
\hline$(-)$-Epicatechin ${ }^{1}$ & $1.04 \pm 0.06$ & $1.11 \pm 0.04$ & $3.54 \pm 0.03$ \\
\hline B-type (epi)catechin trimer ${ }^{1}$ & $1.10 \pm 0.02$ & $1.03 \pm 0.05$ & $1.82 \pm 0.13$ \\
\hline B-type (epi)catechin trimer ${ }^{1}$ & $1.20 \pm 0.02$ & $2.11 \pm 0.02$ & $2.16 \pm 0.08$ \\
\hline Eriodictyol-O-hexoside ${ }^{4}$ & $\operatorname{tr}$ & $\operatorname{tr}$ & $0.16 \pm 0.05$ \\
\hline Quercetin-3-O-glucoside ${ }^{5}$ & nd & $0.88 \pm 0.01$ & $0.97 \pm 0.01$ \\
\hline Total phenolic acids & $5.40 \pm 0.04$ & $3.09 \pm 0.03$ & $2.23 \pm 0.02$ \\
\hline Total flavonoids & $14.19 \pm 0.08$ & $12.44 \pm 0.12$ & $2.95 \pm 0.10$ \\
\hline Total phenolic compounds & $19.59 \pm 0.13$ & $15.53 \pm 0.15$ & $20.49 \pm 0.17$ \\
\hline
\end{tabular}

A. angustifolia (Seccon, Rosa, Freitas, Biavatti, \& Creczynski-Pasa, 2010). Gallic acid and catechin have been identified in cooked and raw A. angustifolia seeds (Koehnlein et al., 2012), whereas, in similar samples, quercetin was identified by two different authors (Cordenunsi et al., 2004; Koehnlein et al., 2012). Catechin has been reported as the main compound present in seeds of $A$. angustifolia (Peralta et al., 2016).

Compounds $1,2,4,5,7,8,10,11$ and 12 were identified as proanthocyanidins based on their pseudomolecular ions and $\mathrm{MS}^{2}$ fragmentation patterns. The analysis of the produced fragments provides information about the type of elementary units and might also inform about their relative position in the proanthocyanidin oligomers. Mass spectra do not, however, allow establishing the position of the linkage between flavanol units (i.e., C4-C8 or C4-C6) nor differentiating between isomeric catechins (e.g., catechin/epicatechin). Compounds 2, 4, 7 and 8 presented the same pseudomolecular ion $[\mathrm{M}-\mathrm{H}]^{-}$at $m / z 577$ and $\mathrm{MS}^{2}$ fragmentation patterns consistent with Btype (epi)catechin dimers (i.e., (epi)catechin units with C4-C8 or C4-C6 interflavan linkages). Characteristic product ions were observed at $\mathrm{m} / \mathrm{z}$ $451(-126 \mathrm{u}), 425(-152 \mathrm{u})$ and $407(-152-18 \mathrm{u})$, attributable to the heterocyclic ring fissions, retro-Diels-Alder and further loss of water from an (epi)catechin unit. Also, ions at $\mathrm{m} / \mathrm{z} 289$ and 287 could be associated with the fragments corresponding to the lower and upper (epi)catechin unit, respectively. Similarly, compounds 10 and 11 (pseudomolecular ions $[\mathrm{M}-\mathrm{H}]^{-}$at $m / z$ 865), could be assigned to Btype (epi)catechin trimers. In all instances, the fragmentation patterns were consistent with those expected for such types of compounds, i.e., similar to those observed for proanthocyanidins dimers but with
Table 4

Extraction yield, DPPH, ABTS and FRAP results for pinhão extracts ( $\left.\mu \mathrm{mol} \mathrm{TE} / \mathrm{g}_{\text {pinhãocoat }}\right)$ : CW (cooking water), EtOH (ethanol extract) and HA (80\%v.v ${ }^{-1}$ ethanol in water extract).

\begin{tabular}{lllll}
\hline Extract & $\begin{array}{l}\text { Extraction Yield } \\
\left(\% \mathrm{wt}^{-1}\right)\end{array}$ & $\begin{array}{l}\text { DPPH } \\
\left(\mu \mathrm{mol} \mathrm{TE} \mathrm{g}^{-1}\right)\end{array}$ & $\begin{array}{l}\text { ABTS } \\
\left.(\mu \mathrm{mol} \mathrm{TE} \mathrm{g})^{-1}\right)\end{array}$ & $\begin{array}{l}\text { FRAP } \\
\left(\mu \mathrm{mol} \mathrm{TE} \mathrm{g}^{-1}\right)\end{array}$ \\
\hline HA & $0.37^{\mathrm{b}} \pm 0.01$ & $8.62^{\mathrm{a}} \pm 1.32$ & $49.10^{\mathrm{b}} \pm 1.01$ & $8.29^{\mathrm{b}} \pm 0.26$ \\
EtOH & $0.15^{\mathrm{a}} \pm 0.01$ & $9.14^{\mathrm{a}} \pm 0.38$ & $26.4^{\mathrm{a}} \pm 0.45$ & $2.12^{\mathrm{a}} \pm 0.03$ \\
CW & $0.57^{\mathrm{c}} \pm 0.02$ & $11.78^{\mathrm{a}} \pm 0.28$ & $54.64^{\mathrm{c}} \pm 2.49$ & $2.09^{\mathrm{a}} \pm 0.01$
\end{tabular}

${ }^{\mathrm{a}, \mathrm{b}}$ Mean \pm standard deviation $(\mathrm{n}=3)$, means from the same column followed by different letters present a significant difference in the extraction treatment $(P<0.05)$ based on Tukey's test.

additional fragments from the alternative cleavages of different interflavan bonds. Compound 1 presented a pseudomolecular ion $[\mathrm{M}-\mathrm{H}]^{-}$ at $m / z 593$, which was tentatively identified as prodelphinidin B3, while compound $5\left([\mathrm{M}-\mathrm{H}]^{-}\right.$at $\left.m / z 355\right)$ was identified as ferulic acid hexoside. Compound $12\left([\mathrm{M}-\mathrm{H}]^{-}\right.$at $\left.m / z 449\right)$ was an eriodictyol-Ohexoside.

Proanthocyanidins and biflavonoids have been previously described as the most abundant compounds in A. angustifolia (Freitas et al., 2009; Peralta et al., 2016; da Silva et al., 2014; Yamaguchi, Kato, \& Di, 2009; Yamaguchi, Vassa, Kato, \& Mascio, 2005). Nevertheless, to the best of our knowledge, a detailed characterization of the proanthocyanidin fraction in A. angustifolia seeds has not been previously described.

Similar phenolic profiles were observed among all the samples, differing only in the amount of the identified compounds. The most abundant molecule present in samples $\mathrm{CW}$ and $\mathrm{EtOH}$ was protocatechuic acid, whereas, for sample HA, (+)-catechin (compound 6) and an (epi)catechin dimer (compound 4) predominated.

\subsection{Antioxidant activity of pinhão extracts}

The extraction yield and antioxidant activity (DPPH, ABTS and FRAP) of the pinhão extracts are presented in Table 4. The initial extraction applied to pinhão, simulated its preparation for consumption, being the residual cooking water (CW) collected. As observed in Table 2, this extract presented the highest solids content. The subsequent EtOH and HA extracts were obtained from the coats of the cooked pinhão, hence, lower extraction yields were obtained. The extraction yields, between EtOH and HA, were significantly different $(P<0.05)$, revealing that water is a good solvent for pinhão coat extraction.

Regarding the DPPH antioxidant activity, there were no significant differences $(P>0.05)$ among the treatments. Previously, Sant'Anna, Sfoglia, Mercali, Corrêa and Brandelli (2016) evaluated the DPPH inhibition capacity of an aqueous pinhão coat extract and obtained up to $87 \%$ inhibition.

In contrast to the DPPH results, ABTS antioxidant activity were significantly different among the extraction treatments $(P<0.05)$. The CW extract was the most effective against the ABTS radical, followed by the HA extract, with the EtOH extract possessing the least ABTS $\cdot{ }^{+}$scavenging activity. Koehnlein et al. (2012) analyzed the ABTS scavenging activity of pinhão coat extracts (70\% ethanol in water) and found $50 \%$ of the radical was scavenged with $52 \mu \mathrm{g} / \mathrm{mL}$ of extract. In the current study, extraction with ethanol led to significantly different FRAP $(P<0.05$ ), compared to extractions using water (CW and HA extracts). Similarly, Bursal and Köksal (2011) also observed that aqueous extracts from sumac (Rhus coriaria L.) presented higher FRAP results than ethanol extracts.

3.3. Mechanical, thermal and microstructural properties of zein films with pinhão extracts

Table 5 summarizes the mechanical properties of the zein films containing the pinhão extracts. Film with HA extract (FHA) presented 
Table 5

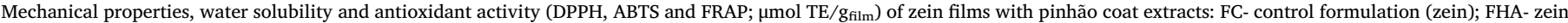
with HA extract; FEtOH- zein with EtOH extract; FCW- zein with CW extract.

\begin{tabular}{|c|c|c|c|c|c|c|c|}
\hline Film & Young Modulus (MPa) & Tensile strenght (MPa) & Elongation at break (\%) & Water solubility (\%) & DPPH $\left(\mu \mathrm{mol} \mathrm{TE} g^{-1}\right)$ & ABTS $\left(\mu \mathrm{mol} \mathrm{TE} / \mathrm{g}^{-1}\right)$ & 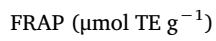 \\
\hline FC & $24.62^{\mathrm{bc}} \pm 11.01$ & $5.80^{\mathrm{a}} \pm 3.70$ & $1.60^{\mathrm{a}} \pm 0.38$ & $54.71^{\mathrm{a}} \pm 1.69$ & $3.10^{\mathrm{a}} \pm 0.12$ & $36.71^{\mathrm{c}} \pm 0.16$ & $18.60^{\mathrm{b}} \pm 1.42$ \\
\hline FHA & $6.16^{\mathrm{a}} \pm 2.25$ & $3.09^{\mathrm{a}} \pm 1.89$ & $1.92^{\mathrm{a}} \pm 0.89$ & $53.77^{\mathrm{a}} \pm 6.08$ & $3.36^{\mathrm{a}} \pm 0.11$ & $22.52^{\mathrm{a}} \pm 0.73$ & $50.84^{c} \pm 1.15$ \\
\hline FEtOH & $33.18^{c} \pm 15.81$ & $7.88^{\mathrm{a}} \pm 6.61$ & $0.98^{\mathrm{a}} \pm 0.53$ & $55.38^{\mathrm{a}} \pm 1.68$ & $3.88^{a} \pm 0.14$ & $33.33^{\mathrm{b}} \pm 0.58$ & $15.96^{\mathrm{ab}} \pm 1.10$ \\
\hline FCW & $23.47^{b c} \pm 2.32$ & $17.65^{\mathrm{b}} \pm 3.67$ & $3.18^{\mathrm{b}} \pm 0.65$ & $73.76^{\mathrm{b}} \pm 1.60$ & $4.88^{\mathrm{a}} \pm 1.90$ & $43.62^{\mathrm{d}} \pm 0.28$ & $13.55^{\mathrm{b}} \pm 0.04$ \\
\hline
\end{tabular}

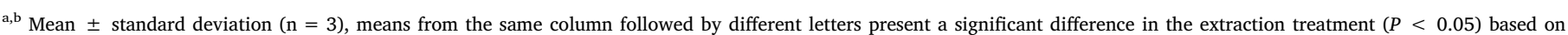
Tukey's test.

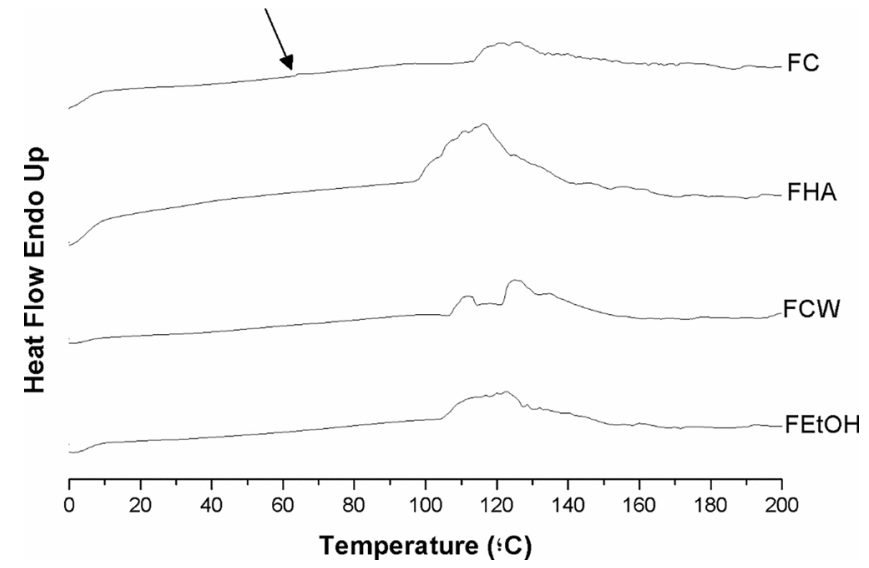

Fig. 2. DSC thermograms of zein films: FC- control formulation (zein); FHA- zein with HA extract; FEtOH- zein with EtOH extract; FCW- zein with CW extract.

the lowest Young's modulus, and this treatment differed statistically from the others $(P<0.05)$. Associated with this, a low tensile strength was also observed, however, the sample prepared with EtOH extract (FEthOH), as well as the control zein formulation (FC) did not differ statistically from the FHA sample $(P>0.05)$. In contrast, the film formulated with CW (FCW) presented a significant increase $(P<0.05)$ in its tensile strength. Likewise, elongation at break significantly increased $(P<0.05)$ in the film with CW. Zein films are known for their brittleness (Lawton, 2004); thus, the addition of CW extract, which improved the plastic behavior of the zein films, provided a strong and tough material, even when compared to the other treatments. This difference may be attributed to the CW extract composition, which was rich in phenolic acids and flavonoids (Table 3). According to Arcan and Yemenicioğlu (2011), the increased flexibility of zein films by the addition of phenolic compounds probably results from the binding of phenolic compounds to the surface of the zein proteins, which leads to an increase in the free volume of the film matrix. Also, a decrease in the hydrophobic interactions among zein molecules may occur due to the action of the hydrophilic groups of the phenolic compounds that contribute to an increase in polymeric chain mobility, eliminating film brittleness.

The CW extract is mainly composed of water-soluble compounds and, proportionally, its solids content is higher than the one present in the other extracts (Table 4, extraction yield results). Accordingly, the FCW film presented a significant increase $(P<0.05)$ in water solubility when compared with the other samples.

In Fig. 2, the DSC thermograms of the zein films are presented. The FC curve revealed a glass transition temperature (Tg) located at $65^{\circ} \mathrm{C}$. Also, two endothermic peaks, around 100 and $160^{\circ} \mathrm{C}$, could be observed for all samples. These peaks are associated with the evaporation of residual water and glycerol, respectively (Kashiri et al., 2016). According to Ghanbarzadeh and Oromiehi (2009), the Tg value of pure zein occurs at $170-180{ }^{\circ} \mathrm{C}$ and decreases to approximately $60-80{ }^{\circ} \mathrm{C}$ in the zein films plasticized by polyols (e.g., glycerol, sorbitol and polyethylene glycol), in agreement with the result shown in Fig. 2. For thermograms of the zein films with extracts (FEtOH, FHA and FCW, respectively), $\mathrm{Tg}$ was not observed, suggesting that it is probably below the evaluated temperature range.

The FEG-SEM images in Fig. 3 shows the morphology of the zein films, both from a surface and fracture perspective. In the fracture images, it is possible to observe that FC, FHA and FEtOH samples present irregular structures that can be associated with their brittle mechanical behavior and low Young's modulus. Also, a porous structure was formed, which has been associated with a fragile behavior (Pizzoli et al., 2016). A rough surface could be observed for all samples, however, the FCW sample was the smoother among the tested treatments.

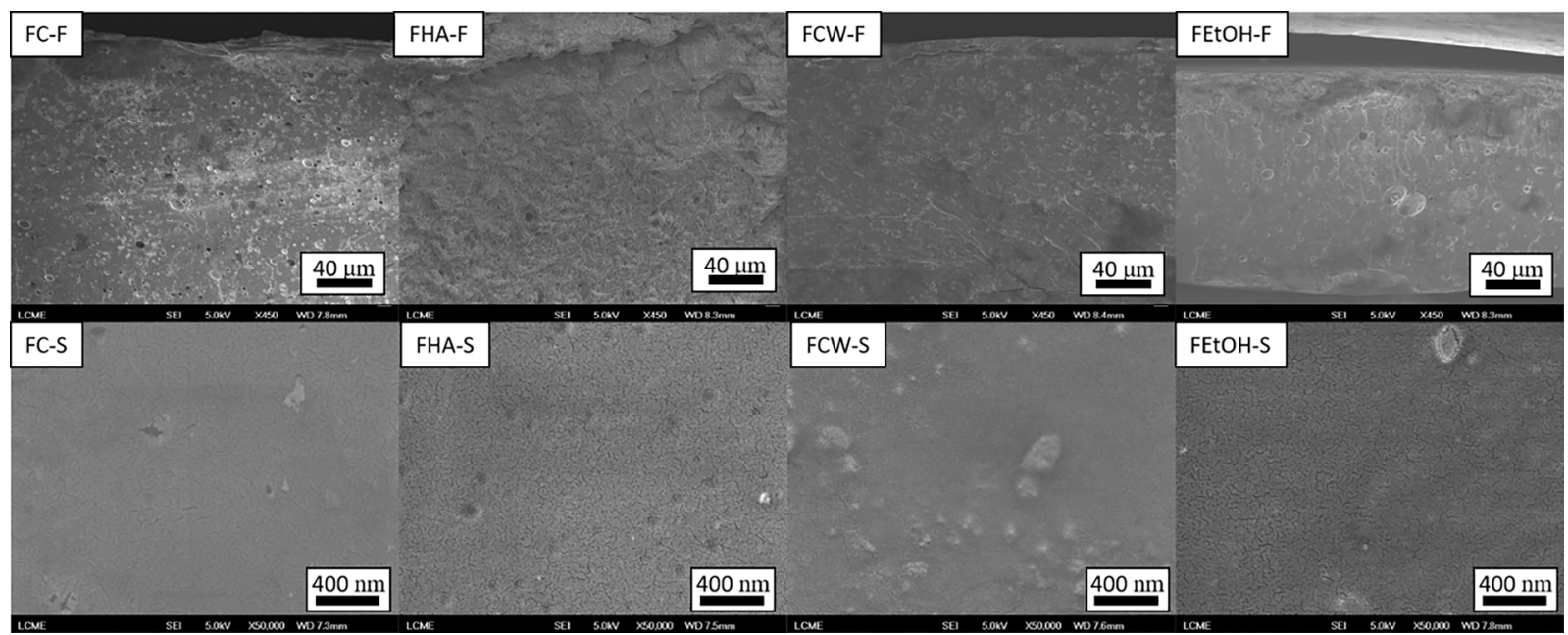

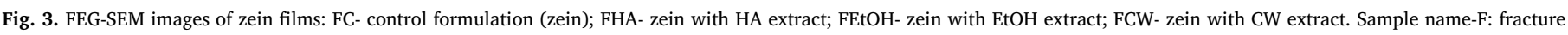
images (450 $\times$ magnification); Sample name-S: surface image (50,000 $\times$ magnification). 


\subsection{Antioxidant activity of zein films with pinhão extracts}

The DPPH, ABTS and FRAP antioxidant activity of the produced films are presented in Table 5. The zein control film (FC) presented antioxidant activity in all performed tests since amino acid residues present antioxidant activity (Zhang, Luo, \& Wang, 2011). In agreement with the antioxidant evaluation of the pinhão coat extracts alone (Table 4), the DPPH results of the corresponding extracted-loaded films were similar $(P>0.05)$. Likewise, ABTS results showed that FCW had the highest ABTS ${ }^{+}$scavenging capacity among the used treatments $(P<0.05)$, corroborating the observed behavior of the extracts (Table 4). Also, the FHA film presented the highest FRAP, comparatively with the other treatments $(P<0.05)$ which is in agreement with results in Table 4.

\section{Conclusions}

Different pinhão coat extracts (cooking water (CW), ethanolic (EtOH) and hydroethanolic (HA)) were obtained and characterized presenting similar phenolic compounds profiles, being protocatechuic acid the most abundant compounds identified in samples CW and EtOH, while $(+)$-catechin and an (epi)catechin dimer predominated in HA sample. Regarding to extracts antioxidant activity, DPPH presented similar results for all samples $(P>0.05)$, although $\mathrm{ABTS}^{+}{ }^{+}$assay showed the following scavenging activity $\mathrm{CW}>\mathrm{HA}>\mathrm{EtOH}$. Zein films formulated with the cooking water of the coated pinhão seeds presented potential as a mechanical properties enhancer since a strong and tough film was obtained (increased tensile strength and elongation at break). The plasticizing effect of the $\mathrm{CW}$ extract on the zein film was also confirmed by the DSC analysis. FEG-SEM images indicated a fragile and brittle behavior of zein films incorporated with $\mathrm{HA}$ and EtOH extracts, respectively.

\section{Acknowledgements}

Authors thank to CNPq (Chamada Universal- MCTI/CNPq № 14/ 2014, Processo 447768/2014-0), CAPES (Master's scholarship) and Fundação Araucária (Programa Universal/Pesquisa Básica e Aplicada 24/2012, protocolo 7334133700514041013) for the finantial support. Project POCI-01-0145-FEDER-006984 - Associated Laboratory LSRELCM funded by FEDER funds through COMPETE2020 - Programa Operacional Competitividade e Internacionalização (POCI) and by national funds through FCT - Fundação para a Ciência e a Tecnologia and to CIMO (UID/AGR/00690/2013).

\section{References}

Arcan, I., \& Yemenicioğlu, A. (2011). Incorporating phenolic compounds opens a new perspective to use zein films as flexible bioactive packaging materials. Food Research International, 44(2), 550-556. http://dx.doi.org/10.1016/j.foodres.2010.11.034.

Arnao, M. B., Cano, A., \& Acosta, M. (2001). The hydrophilic and lipophilic contribution to total antioxidant activity. Food Chemistry, 73(2), 239-244. http://dx.doi.org/10. 1016/S0308-8146(00)00324-1.

Barbosa-Pereira, L., Aurrekoetxea, G. P., Angulo, I., Paseiro-Losada, P., \& Cruz, J. M. (2014). Development of new active packaging films coated with natural phenolic compounds to improve the oxidative stability of beef. Meat Science, 97(2), 249-254. http://dx.doi.org/10.1016/j.meatsci.2014.02.006.

Bello-Pérez, L. A., García-Suárez, F. J., Méndez-Montealvo, G., Do Nascimento, J. R. O., Lajolo, F. M., \& Cordenunsi, B. R. (2006). Isolation and characterization of starch from seeds of Araucaria brasiliensis: A novel starch for application in food industry. Starch/Staerke, 58(6), 283-291. http://dx.doi.org/10.1002/star.200500455.

Benzie, I. F. F., \& Strain, J. J. (1996). The ferric reducing ability of plasma (FRAP) as a measure of antioxidant power: The FRAP assay. Analytical Biochemistry, 239(1), 70-76. http://dx.doi.org/10.1006/abio.1996.0292.

Bessada, S. M. F., Barreira, J. C. M., Barros, L., Ferreira, I. C. F. R., \& Oliveira, M. B. P. P. (2016). Phenolic profile and antioxidant activity of Coleostephus myconis (L.) Rchb.f.: An underexploited and highly disseminated species. Industrial Crops and Products, 89, 45-51. http://dx.doi.org/10.1016/j.indcrop.2016.04.065.

Bitencourt, C. M., Fávaro-Trindade, C. S., Sobral, P. J. A., \& Carvalho, R. A. (2014). Gelatin-based films additivated with curcuma ethanol extract: Antioxidant activity and physical properties of films. Food Hydrocolloids, 40, 145-152. http://dx.doi.org/ 10.1016/j.foodhyd.2014.02.014.
Branco, C. D. S., De Lima, É. D., Rodrigues, T. S., Scheffel, T. B., Scola, G., Laurino, C. C. F. C., ... Salvador, M. (2015). Mitochondria and redox homoeostasis as chemotherapeutic targets of Araucaria angustifolia (Bert.) O. Kuntze in human larynx HEp-2 cancer cells. Chemico-Biological Interactions, 231(July 2016), 108-118. http://dx.doi. org/10.1016/j.cbi.2015.03.005.

Bursal, E., \& Köksal, E. (2011). Evaluation of reducing power and radical scavenging activities of water and ethanol extracts from sumac (Rhus coriaria L.). Food Research International, 44(7), 2217-2221. http://dx.doi.org/10.1016/j.foodres.2010.11.001.

Cervejaria Campos do Jordão (2016). Cerveja pinhão $300 \mathrm{ml}$.

Cheng, S. Y., Wang, B. J., \& Weng, Y. M. (2015). Antioxidant and antimicrobial edible zein/chitosan composite films fabricated by incorporation of phenolic compounds and dicarboxylic acids. LWT - Food Science and Technology, 63(1), 115-121. http:// dx.doi.org/10.1016/j.lwt.2015.03.030.

Conab, C. N.d. A. (2014). CONJUNTURA ESPECIAL PINHÃO (Semente) Setembro de 2014.

Conforti, P. A., \& Lupano, C. E. (2008). Comparative study of the starch digestibility of Araucaria angustifolia and Araucaria araucana seed flour. Starch/Staerke, 60(3-4), 192-198. http://dx.doi.org/10.1002/star.200700671.

Cordenunsi, B. R., De Menezes, E. W., Genovese, M. I., Colli, C., Gonçalves De Souza, A., \& Lajolo, F. M. (2004). Chemical composition and glycemic index of Brazilian pine (Araucaria angustifolia) seeds. Journal of Agricultural and Food Chemistry, 52(11), 3412-3416. http://dx.doi.org/10.1021/jf034814l.

De Araújo, G. K. P., De Souza, S. J., Da Silva, M. V., Yamashita, F., Gonçalves, O. H., Leimann, F. V., \& Shirai, M. A. (2015). Physical, antimicrobial and antioxidant properties of starch-based film containing ethanolic propolis extract. International Journal of Food Science and Technology, 50(9), 2080-2087. http://dx.doi.org/10. 1111/ijfs.12869.

Forato, L. A., Britto, D. De, Scramin, J. A., Colnago, L. A., \& Assis, O. B. G. (2013). Propriedades Mecânicas e Molhabilidade de Filmes de Zeínas Extraídas de Glúten de Milho. Polímeros: Ciência e Tecnologia, 23(1), 42-48. http://dx.doi.org/10.1590/ S0104-14282012005000075.

Freitas, A. M., Almeida, M. T. R., Andrighetti-Fröhner, C. R., Cardozo, F. T. G. S., Barardi, C. R. M., Farias, M. R., \& Simões, C. M. O. (2009). Antiviral activity-guided fractionation from Araucaria angustifolia leaves extract. Journal of Ethnopharmacology, 126(3), 512-517. http://dx.doi.org/10.1016/j.jep.2009.09.005.

Ghanbarzadeh, B., \& Oromiehi, A. R. (2009). Thermal and mechanical behavior of laminated protein films. Journal of Food Engineering, 90(4), 517-524. http://dx.doi.org/ 10.1016/j.jfoodeng.2008.07.018.

Kashiri, M., Cerisuelo, J. P., Domínguez, I., López-Carballo, G., Hernández-Muñoz, P., \& Gavara, R. (2016). Novel antimicrobial zein film for controlled release of lauroyl arginate (LAE). Food Hydrocolloids, 61, 547-554. http://dx.doi.org/10.1016/j. foodhyd.2016.06.012.

Kleen, D., Pauda, G., \& Engeseth, N. (2002). Stabilization of lipids in a biodegradable zein-oleate film by incorporation of antioxidants. Cereal Chemistry, 79, 687-694.

Koehnlein, E. A., Carvajal, A. E. S., Koehnlein, E. M., Coelho-Moreira, J. S., Inácio, F. D., \& Castoldi, R. (2012). Antioxidant activities and phenolic compounds of raw and cooked Brazilian pinhão (Araucaria angustifolia) seeds. African Journal of Food Science, 6, 512-518.

Lawton, J. W. (2004). Plasticizers for zein: Their effect on tensile properties and water absorption of zein films. Cereal Chemistry, 81(1), 1-5. http://dx.doi.org/10.1094/ CCHEM.2004.81.1.1.

Lee, S. H., Lee, M. S., \& Song, K. B. (2004). Physical properties of protein films containing green tea extract and its antioxidant effect on fish paste products. Journal of the Korean Society of Food Science and Nutrition, 1, 10-15.

Lima, E. C., Royer, B., Vaghetti, J. C. P., Brasil, J. L., Simon, N. M., dos Santos, A. A., ... Silva, E. A.d. (2007). Adsorption of Cu(II) on Araucaria angustifolia wastes: Determination of the optimal conditions by statistic design of experiments. Journal of Hazardous Materials, 140(1-2), 211-220. http://dx.doi.org/10.1016/j.jhazmat.2006. 06.073.

Mensor, L. L., Menezes, F. S., Leitão, G. G., Reis, A. S., Santos, T. C., dos Coube, C. S., \& Leitão, S. G. (2001). Screening of Brazilian plant extracts for antioxidant activity by the use of DPPH free radical method. Phytotherapy Research, 130, 127-130. http://dx. doi.org/10.1002/ptr.687.

Neo, Y. P., Ray, S., Jin, J., Gizdavic-Nikolaidis, M., Nieuwoudt, M. K., Liu, D., \& Quek, S. Y. (2013). Encapsulation of food grade antioxidant in natural biopolymer by electrospinning technique: A physicochemical study based on zein-gallic acid system. Food Chemistry, 136(2), 1013-1021. http://dx.doi.org/10.1016/j.foodchem.2012.09.010.

Oliveira, R., Gonçalves, G., Inácio, F., Koehnlein, E., de Souza, C., Bracht, A., \& Peralta, R. (2015). Inhibition of pancreatic lipase and triacylglycerol intestinal absorption by a Pinhão Coat (Araucaria angustifolia) extract rich in condensed tannin. Nutrients, 7(7), 5601-5614. http://dx.doi.org/10.3390/nu7075242.

Park, H.-Y., Kim, S.-J., Kim, K. M., You, Y.-S., Kim, S. Y., \& Han, J. (2012). Development of antioxidant packaging material by applying corn-zein to LLDPE film in combination with phenolic compounds. Journal of Food Science, 77(10), E273-279. http://dx. doi.org/10.1111/j.1750-3841.2012.02906.x.

Peralta, R. M., Koehnlein, E. A., Oliveira, R. F., Correa, V. G., Corrêa, R. C. G., Bertonha, L., ... Ferreira, I. C. F. R. (2016). Biological activities and chemical constituents of Araucaria angustifolia: An effort to recover a species threatened by extinction. Trends in Food Science and Technology, 54, 85-93. http://dx.doi.org/10.1016/j.tifs.2016.05. 013.

Phiriyawirut, M., \& Maniaw, P. (2012). Cellulose microfibril from banana peels as a nanoreinforcing fillers for zein films. Open Journal of Polymer Chemistry, 2, 56-62.

Pizzoli, A. P. D. O., Marchiore, N. G., De Souza, S. J., De Freitas Santos, P. D., Gonçalves, O. H., Yamashita, F., ... Leimann, F. V. (2016). Antimicrobial PLA/TPS/gelatin sheets with enzymatically crosslinked surface containing silver nanoparticles. Journal of Applied Polymer Science, 133(8), 1-8. http://dx.doi.org/10.1002/app.43039.

Riele Conservas (2016). Pinhão tradicional. 
Sant'Anna, V., Sfoglia, N. M., Mercali, G. D., Corr, A. P. F., \& Brandelli, A. (2016). Original article Effect of cooking on polyphenols and antioxidant activity of Araucaria angustifolia seed coat and evaluation of phytochemical and microbiological stability over storage. International Journal of Food Science \& Technology, 1932-1936. http:// dx.doi.org/10.1111/ijfs.13170.

Santos, F. A., Idrees, M., Silva, M., de Lima, P. H. E., Bueno, N., Nome, F., ... Pires, M. (2013). Cr(III) biosorption by forest wastes from Araucaria angustifolia and Pinus elliottii: Biosorbent surface characterization and chromium quantification by spectrofluorimetry in micellar medium. Desalination and Water Treatment, 51(28-30), 5617-5626. http://dx.doi.org/10.1080/19443994.2012.758600.

Seccon, A., Rosa, D. W., Freitas, R.a., Biavatti, M. W., \& Creczynski-Pasa, T. B. (2010) Antioxidant activity and low cytotoxicity of extracts and isolated compounds from Araucaria angustifolia dead bark. Redox Report: Communications in Free Radical Research, 15(6), 234-242. http://dx.doi.org/10.1179/ 135100010 X12826446921789.

Thaipong, K., Boonprakob, U., Crosby, K., Cisneros-Zevallos, L., \& Hawkins Byrne, D. (2006). Comparison of ABTS, DPPH, FRAP, and ORAC assays for estimating antioxidant activity from guava fruit extracts. Journal of Food Composition and Analysis, 19(6-7), 669-675. http://dx.doi.org/10.1016/j.jfca.2006.01.003.
WWC (2016). Pinhão em conserva.

Yamaguchi, L. F., Vassa, D. G., Kato, M. J., Mascio, \& Di, P. (2005). Biflavonoids from Brazilian pine Araucaria angustifolia as potentials protective agents against DNA damage and lipoperoxidation. Phytochemistry, 66, 2238-2247. http://dx.doi.org/10. 1016/j.phytochem.2004.11.014.

Yamaguchi, L. F., Kato, M. J., \& Di, P. (2009). Phytochemistry biflavonoids from araucaria angustifolia protect against DNA UV-induced damage. Phytochemistry, 70(5), 615-620. http://dx.doi.org/10.1016/j.phytochem.2009.03.003.

Zhang, B., Luo, Y., \& Wang, Q. (2011). Effect of acid and base treatments on structural, rheological, and antioxidant properties of a-zein. Food Chemistry, 124(1), 210-220. http://dx.doi.org/10.1016/j.foodchem.2010.06.019.

da Mota, G. S. T., Arantes, A. B., Sacchetti, G., Spagnoletti, A., Ziosi, P., Scalambra, E., ... Manfredini, S. (2014). Antioxidant activity of cosmetic formulations based on novel extracts from seeds of brazilian araucaria angustifolia (Bertoll) Kuntze. Journal of Cosmetics, Dermatological Sciences and Applications, 4, 190-202.

da Silva, S. M., Koehnlein, E. A., Bracht, A., Castoldi, R., de Morais, G. R., Baesso, M. L., ... Peralta, R. M. (2014). Inhibition of salivary and pancreatic $\alpha$-amylases by a pinhão coat (Araucaria angustifolia) extract rich in condensed tannin. Food Research International, 56, 1-8. http://dx.doi.org/10.1016/j.foodres.2013.12.004. 